overview and contains a substantial bibliography. One or two comments were rather surprising, however, especially the likening of greenstone belts to Mesozoic continental flood basalts.

The following three chapters deal with the formation, migration and accumulation of petroleum. Much of the material is a duplication of that to be found in any petroleum geology text. Plate tectonics is certainly dealt with in terms of basin development, but in view of the volume's title and its stated goals, this important subject deserved a more penetrating analysis and further fleshing-out with specific examples. Chapter 5 provides the reader with an overview of coal geology; again, much of the material is standard textbook stuff, and the chapter contains only half a page of general comments regarding possible plate tectonic controls of coal-generating environments.

The remainder of the book covers the relationships of metal deposits to plate tectonics. The chapter dealing with metal deposits formed at spreading ridges is well done and covers podiform chromite and Cyprus-type massive sulphide deposits. However, the association of ore deposits with subduction-related environments is covered in a mere seven pages of text, plus four illustrations; as a result of this brevity, many important types of deposits in subduction-related arcs are ignored, as are most of the more recent insights into arcmetal deposit relationships such as interarc rifting.

The contribution on the origins of ore deposits in sedimentary rocks is certainly of adequate length and contains a good deal of information, although the writing is somewhat laboured. I was also confused by the author's lack of conviction on certain points. For example, less than a page after a statement that the relationship between

"secondary sedimentary ores and some sort of growth faulting is so common as to be almost a requirement", the suggestion that rifting is active during mineralization is questioned.

The final chapter considers the significance of palaeoclimatic factors on resources and offers some general conclusions. It touches briefly on a host of varied topics, but contains one or two startling misconceptions, for example the suggestion that the copper-sulphide deposits of Kennecott, Alaska, have a detrital orgin.

The volume contains 64 figures, many of them rather simple sketches, and only a single table. There are also a number of text citations missing in the references.

Overall, one is left with the impression of a somewhat hastily assembled volume which falls short of its claim to "provide an integrated introduction to the subject of economic geology"'.

Frederick J. Sawkins is a Professor in the Department of Geology and Geophysics at the University of Minnesota.

\title{
Solving big problems on big computers
}

\section{F. James}

Computer Simulation Using Particles. By Roger W. Hockney and James W. Eastwood. Pp.540. ISBN 0-07-029108-X. (McGraw-Hill: 1981.) \$49.50, £27.50.

IT IS a pleasure, in these days of makeshift books on computing and simulation, to come across a thoroughly coherent work painstakingly prepared by recognized experts in the field.

The authors address themselves to one of the three general approaches to the study of systems (liquids, galaxies, plasmas and so on) governed by known differential equations. The other two approaches, finite elements and finite differences, are already well covered in the literature, whereas direct simulation by following constituent "particles" of the system, although in many ways more interesting mathematically, has largely been ignored except in research papers. To say that this book fills the gap is something of an understatement.

The orientation of the book is truly that of computational physics (or, as the authors prefer, computational science). It is not just a physics book with a chapter on FORTRAN at the end. Although the subject is problems arising in physics and related areas, suitability to computation is the overriding criterion for all of the material presented; no model or technique is suggested which has not been used in actual computations, more often than not by the authors themselves.

Considerable attention is paid even to programming methodology, including a rather complete account of the OLYMPUS programming system. Such a chapter could, of course, be grafted onto any book, but it finds a natural place in this work where the coverage of fundamental properties of algorithms includes not only their theoretical convergence rates, stability and such, but also actual computer time and storage requirements, arithmetic precision requirements and sometimes suitability to particular computer architectures. The usefulness of this aspect could have been enhanced still further by including a table of comparison of different computers' performance, since of the computers most often cited (IBM 7090, 360/91 and $360 / 195$, CDC 6600 and 7600 , ILLIAC IV, CRAY-1) most are rare birds, technologically obsolescent or both, and, apart from the CRAY, are unlikely to be commonly available in a few years' time.

Physicists will appreciate the authors' basic approach, the mathematical notation

Volume III of The Northwest European Pollen Flora has been published by Elsevier Scientific. Containing detailed studies of the pollen morphology of a further eight families, the book costs Dfl.110, $\$ 53.75$. and the vocabulary. The reader is encouraged to consider the problems in their physical context, not just as mathematical abstractions. The importance of physical insight in the choice of mathematical methods is brought out clearly. In addition, the interdisciplinary nature of the work should make it especially interesting, for example, to an astronomer who can see the relationships between problems arising in the study of the orbits of galaxies and in the design of transistors.

The style of the book is characterized by clarity and simplicity, the hallmarks of authors who have something of substance to say and possess a complete grasp of their subject. The quality of the printing, the pleasant layout of text and, especially, the numerous and helpful illustrations (many computer-produced, of course) all contribute towards making the book a real pleasure to read. It is a first-rate reference book which will be indispensable to workers in the field, and it will certainly find its place as a textbook for advanced courses in both computer science and physics, as well as intermediate fields.

Frederick James is a staff physicist in the Data Handling Division of CERN, and a past chairman of the Computational Physics Group of the European Physical Society.

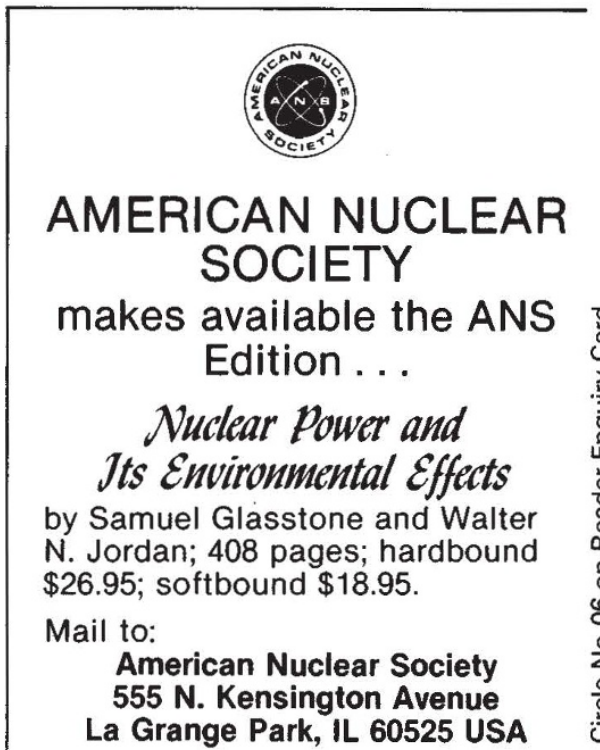

Name

Address

City

State/Province

Country Zip

Please take my order for books.

Payment in full enclosed.

Bill me and I accept postage and handling charges. 